\title{
Therapeutic effect of neutralizing endogenous IL-18 activity in the collagen-induced model of arthritis
}

\author{
Christine Plater-Zyberk, ${ }^{1}$ Leo A.B. Joosten, ${ }^{2}$ Monique M.A. Helsen, ${ }^{2}$ \\ Pascale Sattonnet-Roche, ${ }^{1}$ Christiane Siegfried, ${ }^{1}$ Sami Alouani, ${ }^{1}$ Fons A.J. van de Loo, ${ }^{2}$ \\ Pierre Graber, ${ }^{1}$ Shuki Aloni, ${ }^{3}$ Rocco Cirillo, ${ }^{4}$ Erik Lubberts, ${ }^{2}$ Charles A. Dinarello, ${ }^{5}$ \\ Wim B. van den Berg, ${ }^{2}$ and Yolande Chvatchko ${ }^{1}$ \\ 1Serono Pharmaceutical Research Institute, Geneva, Switzerland
${ }^{2}$ Rheumatology Research Laboratory, University Medical Center Nijmegen, Nijmegen, The Netherlands
${ }^{3}$ InterPharma Laboratories, Nes Ziona, Israel
${ }^{4}$ Istituto Di Ricerche Biomedche Antoine Marxer, Collereto Giacosa, Italy
${ }^{5}$ Department of Medicine, University of Colorado Health Sciences Center, Denver, Colorado, USA \\ Address correspondence to: Yolande Chvatchko, Serono Pharmaceutical Research Institute 14, \\ Chemin des Aulx CH-1228 Plan-les-Ouates, Geneva, Switzerland. \\ Phone: 41-22-706-9792; Fax: 41-22-794-6965; E-mail: yolande.chvatchko@serono.com.
}

Christine Plater-Zyberk and Leo A.B. Joosten contributed equally to this work.

Received for publication January 3, 2001, and accepted in revised form October 22, 2001.

\begin{abstract}
Two distinct IL-18 neutralizing strategies, i.e. a rabbit polyclonal anti-mouse IL-18 IgG and a recombinant human IL-18 binding protein (rhIL-18BP), were used to treat collagen-induced-arthritic DBA/ 1 mice after clinical onset of disease. The therapeutic efficacy of neutralizing endogenous IL-18 was assessed using different pathological parameters of disease progression. The clinical severity in mice undergoing collagen-induced arthritis was significantly reduced after treatment with both IL-18 neutralizing agents compared to placebo treated mice. Attenuation of the disease was associated with reduced cartilage erosion evident on histology. The decreased cartilage degradation was further documented by a significant reduction in the levels of circulating cartilage oligomeric matrix protein (an indicator of cartilage turnover). Both strategies efficiently slowed disease progression, but only anti-IL-18 IgG treatment significantly decreased an established synovitis. Serum levels of IL-6 were significantly reduced with both neutralizing strategies. In vitro, neutralizing IL-18 resulted in a significant inhibition of TNF- $\alpha$, IL- 6 , and IFN- $\gamma$ secretion by macrophages. These results demonstrate that neutralizing endogenous IL-18 is therapeutically efficacious in the murine model of collagen-induced arthritis. IL-18 neutralizing antibody or rhIL-18BP could therefore represent new disease-modifying anti-rheumatic drugs that warrant testing in clinical trials in patients with rheumatoid arthritis.
\end{abstract}

J. Clin. Invest. 108:1825-1832 (2001). DOI:10.1172/JCI200112097.

\section{Introduction}

IL-18 is a member of the IL- 1 cytokine family that was originally identified as IFN- $\gamma$-inducing factor (1). Similar to IL-12, IL-18 stimulates Th1 cell differentiation (2, $3)$, promotes IFN- $\gamma$, TNF- $\alpha$, IL- $1 \beta$, IL- 8 , and GM-CSF secretion (4-6), and enhances natural killer cell cytotoxicity $(7,8)$. The precursor to IL-18, pro-IL-18, is cleaved by IL- $1 \beta$-converting enzyme (also known as caspase-1), resulting in the active $18-\mathrm{kDa}$ mature protein (9). Pro-IL-18 expression has been detected in antigenpresenting cells such as activated macrophages, Kupffer cells (7), dendritic cells (10), and Langerhans cells (11), as well as articular chondrocytes (12) and osteoblasts (13). The receptor complex for IL-18, IL-18R, is comprised of an $\alpha$ chain and a nonbinding $\beta$ chain, both members of the IL-1R family. This receptor complex signals through a pathway that involves myeloid differentiation factor 88, IL-1 receptor-associated kinase, TNF

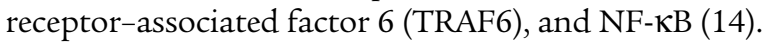

Recent studies have elucidated a broad spectrum of effector functions beyond lymphocyte activation that implicate IL-18 as an important regulator of chronic inflammation in human autoimmune diseases (15). It has recently been reported that elevated levels of IL-18 were observed in synovial fluid from patients with rheumatoid arthritis (16). IL-18 induces TNF- $\alpha$, GM-CSF, IFN- $\gamma$, and nitric oxide production by synovial cells isolated from patients with rheumatoid arthritis through a direct, IFN- $\gamma$-independent pathway, via constitutive IL-18R $\alpha$ expression (16). The IL-18-induced cytokine production by synovial macrophages was potentiated by IL-12 and/or IL-15, and was suppressed by IL- 10 and TGF- $\beta$. Moreover, IL- $1 \beta$ induces mature IL-18 expression in human articular chondrocytes through a caspase-1-dependent pathway (12). IL-18 induces chondrocyte proliferation, upregulates inducible nitric oxide synthase, stromelysin, and cyclooxygenase-2 expression, and increases gly- 
cosaminoglycan release (17). More recently, neutralization of endogenous IL-18 during the onset of disease in an acute streptococcal wall-induced joint inflammation significantly reduced local TNF- $\alpha$ and IL- $1 \beta$ levels (18). These data indicate that IL-18 could modulate synovial inflammation during rheumatoid arthritis, and could therefore represent a novel therapeutic target.

IL-18 binding protein (IL-18BP), a constitutively expressed and secreted protein, has been identified (19, 20). IL-18BP binds IL-18 with high affinity ( $400 \mathrm{pM})$, and blocks its biological activity at a 1:1 molar ratio (21). Such a naturally occurring molecule represents an interesting inhibitor for testing in experimental models of disease. Administration of collagen type II and CFA in DBA/ 1 mice is a well-established animal model of rheumatoid arthritis. In this model, immunization with type II collagen induces the development of an erosive, inflammatory arthritis (22), and represents an ideal opportunity to explore the therapeutic potential of novel molecules (23-25). To this end, endogenous IL-18 was neutralized in mice with collagen-induced arthritis (CIA) using either IL-18 neutralizing antibody or recombinant human IL-18BP (rhIL-18BP), and the effects of these treatments were evaluated by different parameters of pathogenicity.

\section{Methods}

Induction of CIA. CIA was induced in 8- to 12-week-old male DBA/1 mice obtained from Bomholdgard Breeding and Research Centre Ltd. (Ry, Denmark) for the anti-IL-18 treatment, and from Charles River Japan Inc. (Shin-Yokohama, Japan) for treatment with rhIL-18BP. All mice were immunized with native type II bovine collagen (CII) in emulsified CFA as previously described (24). Mice used in the anti-IL-18 antibody experiments received an additional intraperitoneal immunization with $100 \mu \mathrm{g}$ of $\mathrm{CII}$ in saline at day 21 (26). Starting on day 25 after immunization, mice were examined daily for onset of disease, which occurs between days 25 and 30 .

Treatment with rabbit anti-IL-18 IgG and rhIL-18BP. Therapeutic treatment of CII-immunized DBA/ 1 mice was started at the first appearance of clinical signs of disease (between days 21 and 30). Two strategies were used to neutralize endogenous IL-18. The first was a single intraperitoneal injection ( $2 \mathrm{mg}$ per mouse) of neutralizing rabbit anti-IL-18 IgG, prepared by HiTrap Protein G HP (Amersham Pharmacia Biotech AB, Uppsala, Sweden). This dose was shown to be effective in the murine models of LPS-mediated lethal shock (27) and streptococcal cell wall-induced arthritis (18). Control mice received normal rabbit IgG. The second neutralizing agent used was rhIL-18BP isoform a, which was labeled at the $\mathrm{N}$-terminal with six histamines (rhIL-18BPa-6his). This was expressed in Chinese hamster ovary cells and purified to homogeneity (21), then injected intraperitoneally daily for 7 days at four different concentrations: $0.25,0.5,1$, and $3 \mathrm{mg} / \mathrm{kg}$; in this protocol, the control mice received vehicle only $(0.9 \% \mathrm{NaCl})$.
Clinical evaluation of disease progression. From the first appearance of clinical signs of disease, mice were examined by an investigator blinded to the treatment. Each limb was graded for disease severity (clinical scores, $0-3.5$; maximum score, 14 /mouse). The progression of swelling (inflammation) was measured on the paw that first showed signs of disease, using precision calipers (Brutsch Ruegger AG, Zurich, Switzerland). Disease progression was monitored daily for 8 days in rhIL-18BP-treated mice, and every other day for 15 days in mice treated with anti-IL-18 IgG.

Histological assessment of cartilage erosions and synovial inflammation. At the termination of the experiments, mice were sacrificed, and the paws were prepared for histological analysis. Joints were fixed, decalcified, and embedded in paraffin. Cryosections $(5-7 \mu \mathrm{m})$ were stained with hematoxylin/eosin and safranin O. Each joint was scored separately by two individuals who were unaware of the treatment protocol, using the following erosion scoring scale: no destruction of cartilage or bone $=0$; localized cartilage erosions $=1-2$; more extended erosions $=3$; general cartilage destruction and presence of bone erosions $=4$. The final score of each mouse was the mean of all joints scored. Synovial inflammation (infiltration and hyperplasia) was scored from 0 to 4, as follows: no inflammation $=0$; slight thickening of lining layer and/or some infiltrating cells in the sublining layer $=1-2$; thickening of lining layer and/or a more pronounced influx of cells in the sublining layer $=3$; presence of cells in the synovial space, thickening of lining layer, and synovium highly infiltrated with numerous inflammatory cells $=4$.

Murine IL-18BP and rbIL-18BP quantification. To measure plasma levels of endogenous murine IL-18BP (mIL-18BP), 96-well plates (Combiplate $12 \mathrm{~EB}$; Bioconcept, Allschwil, Switzerland) were coated with $0.5 \mu \mathrm{g} / \mathrm{ml}$ of an affinity purified rabbit polyclonal antibody to recombinant murine IL-18BPd isoform d, (rmIL-18BPd). Plasma mIL-18BP was detected using a biotinylated rabbit polyclonal antibody raised against $E$. coli rmIL-18BP (PeproTech Inc., Rocky Hill, New Jersey, USA), followed by extravidin-peroxidase conjugate diluted 1:10,000 (Sigma Chemical Co., St. Louis, Missouri, USA). rmIL-18BPd produced by HEK 293 cells was used as a standard. The sensitivity of the ELISA used was $5 \mathrm{ng} / \mathrm{ml}$.

To measure plasma levels of rhIL-18BP, 96-well plates (Combiplate $12 \mathrm{~EB}$; Bioconcept) were coated with 0.2 $\mu \mathrm{g} / \mathrm{ml}$ of an affinity purified rabbit polyclonal antibody to rhIL-18BPa. Circulating rhIL-18BPa was then detected using $500 \mathrm{ng} / \mathrm{ml}$ of anti-rhIL-18BPa biotinylated monoclonal antibody (clone 657.27), followed by extravidin-peroxidase conjugate diluted 1:10,000 (Sigma Chemical Co.). rhIL-18BPa-6his was used as a standard. The sensitivity of the ELISA used was $50 \mathrm{pg} / \mathrm{ml}$.

Cartilage oligomeric matrix protein measurements. At the termination of the experiments, serum samples were collected, and an ELISA to determine cartilage oligomeric matrix protein (COMP) levels was performed as previously described (28). 
Cytokine assays. Levels of immunoreactive mIL-6 (R\&D Systems Inc., Oxon, United Kingdom) and mIL18 (Medical and Biological Laboratories Co., Nagoya, Japan) were determined using ELISA. The detection limit for mIL-6 was $15 \mathrm{pg} / \mathrm{ml}$; that for mIL-18 was 25 $\mathrm{pg} / \mathrm{ml}$. mIL- 6 bioactivity was determined by a proliferative assay using $\mathrm{B} 9$ cells. The detection limit for the mIL-6 bioassay was $1 \mathrm{pg} / \mathrm{ml}$.

Peritoneal macrophage culture. Peritoneal macrophages from DBA/ 1 mice were enriched by adherence. Enriched macrophages (97\%) were cultured in supplemented RPMI 1640 medium at $2 \times 10^{6}$ cells $/ \mathrm{ml}$ in flat 96-well plates (Nalge Nunc International, Roskilde, Denmark) in the presence of mIL-12 (100 ng/ml), mIL-18 (200 $\mathrm{ng} / \mathrm{ml}$; R\&D Systems Inc.), and rhIL-18BP $(1 \mu \mathrm{g} / \mathrm{ml})$ for 24 hours. The supernatants were assayed for cytokines by ELISA according to the manufacturer's instructions (R\&D Systems Inc.). Detection limits were: $\operatorname{mIFN}-\gamma, 31$ $\mathrm{pg} / \mathrm{ml}, \mathrm{mIL}-6$ and $\mathrm{mTNF}-\alpha, 15 \mathrm{pg} / \mathrm{ml}$.

Expression of results. Results are expressed as difference from the first day of treatment and as area under the curve. The area under the curve is a cumulative measure of the effect during the entire experiment, determined using the formula $\mathrm{d} x\left(y_{1}+y_{2}\right) / 2$.

Statistical analysis. Significance of differences was assessed by the Mann-Whitney $U$ test using the SigmaStat statistical analysis program (SPSS Inc., Chicago, Illinois, USA) and the GraphPad Prism program (GraphPad Software Inc., San Diego, California, USA).

\section{Results}

IL-18 levels are increased in the sera of mice with CIA. On days 4 and 8 after the onset of CIA, circulating levels of IL-18 were significantly elevated $(320 \pm 56 \mathrm{pg} / \mathrm{ml}$ and $171 \pm 62$ $\mathrm{pg} / \mathrm{ml}$, respectively) compared with the levels measured in naive mice of the same strain $(58 \pm 34 \mathrm{pg} / \mathrm{ml}, P=0.0012, n=6$ in each group). This observation demonstrates induction of endogenous IL-18 during the clinical expression of CIA. Endogenous levels of mIL-18BP were below 5 $\mathrm{ng} / \mathrm{ml}$, the detection limit of the ELISA.

Neutralization of endogenous $I L-18$ decreases the severity of CIA. In order to investigate whether blocking endogenous IL-18 could represent a new therapy for rheumatoid arthritis, two different IL-18 neutralizing agents were administered to mice shortly after clinical onset of CIA. In the first set of experiments, mice received a single intraperitoneal injection of neutralizing anti-IL-18 polyclonal IgG (2 mg). This treatment resulted in a significant reduction in disease severity compared with the control CIA group, which received $2 \mathrm{mg}$ of normal rabbit $\operatorname{IgG}(P=0.0001)$ (Figure 1 , a and $c)$. In the second set of experiments, a dose-related study was performed using rhIL-18BP. Arthritic DBA/1 mice were treated daily, starting at the first sign of disease, with four different doses of rhIL-18BP $(0.25 \mathrm{mg} / \mathrm{kg}, 0.5 \mathrm{mg} / \mathrm{kg}, 1 \mathrm{mg} / \mathrm{kg}$, and 3 $\mathrm{mg} / \mathrm{kg}$, intraperitoneal). Control mice with CIA received vehicle only $(\mathrm{NaCl})$. As shown in Figure 1, b and $d$, the severity of disease was significantly diminished in the groups treated with rhIL-18BP at $0.5,1$, and $3 \mathrm{mg} / \mathrm{kg}(P=0.01, P=0.002$, and $P=0.03$, respectively). Mice receiving the lower dose of rhIL-18BP $(0.25$ $\mathrm{mg} / \mathrm{kg}$ ) exhibited clinical scores that were not statistically different from the CIA control group.

Neutralization of IL-18 activity protects joints from destruction. Both treatments, anti-IL-18 IgG and rhIL-18BP, resulted in protection of joints from destruction. Figure 2 shows representative photomicrographs of joints from naive mice (Figure 2, a and d), arthritic mice (Figure $2, \mathrm{~b}$ and $\mathrm{e})$, and arthritic mice treated therapeutically with $2 \mathrm{mg} /$ mouse of anti-IL-18 IgG (Figure 2c) and $3 \mathrm{mg} / \mathrm{kg}$ rhIL-18BP (Figure 2f). Joints from the arthritic control mice showed the expected severe inflammation of the synovium, with thickening of the lining layer, infiltration by inflammatory cells, and presence of pannus overlaying the cartilage. Cartilage and subchondral bone erosions were also present (Figure 2, b and e). Cartilage destruction was further demonstrated by the depletion of matrix proteoglycan,
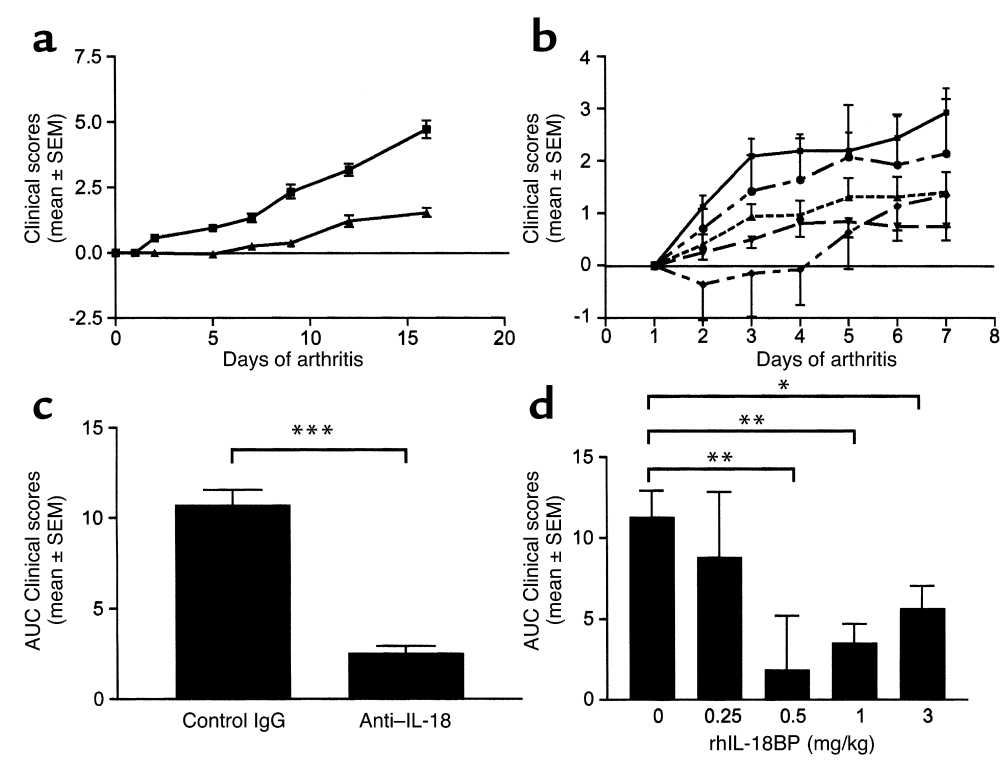

Figure 1

Neutralization of endogenous IL-18 decreases disease severity in CIA mice. ( $\mathbf{a}$ and $\mathbf{b}$ ) Changes in clinical scores over time in DBA/1 mice with type II CIA. CIA mice were treated intraperitoneally when the first clinical signs of arthritis appeared with: (a) control IgG (2 mg/mouse) (squares), or anti-mIL-18 IgG (2 mg/mouse) (triangles) ( $n=9$, for each dose); and (b) with saline (squares) $(n=16)$ or rhIL-18BP: 0.25 $\mathrm{mg} / \mathrm{kg}$ (circles), $0.5 \mathrm{mg} / \mathrm{kg}$ (diamonds) ( $n=7$, for each dose), $1 \mathrm{mg} / \mathrm{kg}$ (inverted triangles), and $3 \mathrm{mg} / \mathrm{kg}$ (triangles) ( $n=16$, for each dose). Disease development was monitored as described in Methods. (c and $\mathbf{d}$ ) The same results are expressed as the mean area under the curve $(A \cup C) \pm S E M$ of the clinical scores from the first to the last day of the experiment after treatment with anti-IL-18 IgG (c) and rhIL-18BP(d). ${ }^{*} P<0.05,{ }^{*} P<0.001,{ }^{*}{ }^{*} P<0.0001$, treated versus control groups. 


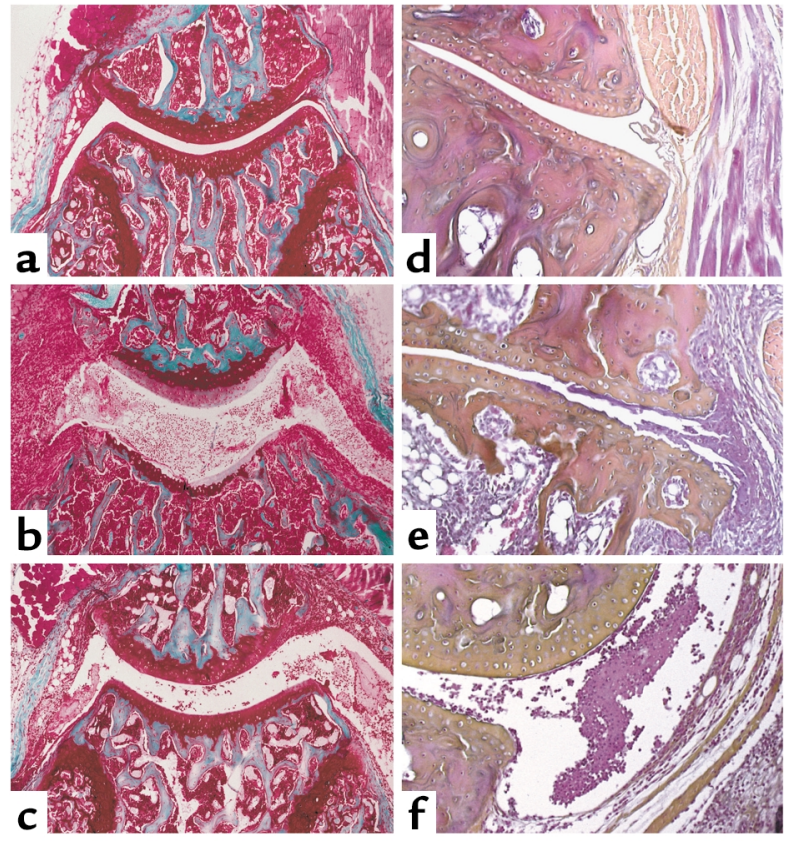

Figure 2

IL-18 neutralization decreases inflammation and cartilage degradation. At the end of the experiment, the paw that first developed arthritis was dissected away, fixed, and processed as described in Methods. (a-c) Safranin O staining. (d-f) Hematoxylin and eosin staining. (a and d) Normal mouse joint. Joint from control CIA mouse treated with $2 \mathrm{mg}$ control $\operatorname{lgG}(\mathbf{b})$ and with saline (e) showing severe arthritis with cartilage destruction and proteoglycan depletion, with numerous infiltrating cells in the inflamed synovium and synovial space. (c and $\mathbf{f}$ ) Joints from mouse treated with $2 \mathrm{mg}$ of anti-mIL-18 IgG (c) or with $3 \mathrm{mg} / \mathrm{kg}$ rhIL-18BP (f). The cartilage appears well protected despite the presence of inflammatory cells. Original magnification: $\times 100(\mathbf{a}-\mathbf{c})$ and $\times 200(\mathbf{d}-\mathbf{f})$.

as evidenced by safranin $\mathrm{O}$ staining (Figure $2 \mathrm{~b}$ ). In contrast, joints from CIA mice treated with anti-IL-18 IgG (2 $\mathrm{mg} /$ mouse) and rhIL-18BP $(3 \mathrm{mg} / \mathrm{kg})$ showed markedly less cartilage and fewer bone erosions (Figure $2, \mathrm{c}$ and $\mathrm{f}$. Loss of matrix proteoglycan content in the cartilage was also much lower, as illustrated by the deep pink color of the cartilage (Figure 2c), which looked similar in staining to the normal cartilage (Figure 2a). However, inflammatory cells, although reduced in the synovium of the treated mice, were still present, and many cells were seen in the synovial space (Figure 2, c and $f$ ). A semiquantitative scoring system confirmed that cartilage erosions were significantly reduced in the joints of mice that received anti-IL-18 IgG and the higher doses of $1 \mathrm{mg} / \mathrm{kg}$ and $3 \mathrm{mg} / \mathrm{kg}$ rhIL-18BP, compared with CIA control mice $(P=0.006, P=0.05$, and $P=0.036$, respectively) (Figure $3 \mathrm{a}$ ). No protection was observed at doses of $0.5 \mathrm{mg} / \mathrm{kg}$ or $0.25 \mathrm{mg} / \mathrm{kg}$ rhIL-18BP (Figure 3a). Histological analysis of three paws (the first arthritic paw was excluded) confirmed the reduction in erosion scores resulting from treatment with 1 and $3 \mathrm{mg} / \mathrm{kg}$ rhIL-18BP compared with saline-treated CIA mice $(1.92 \pm 1.6, n=30 ; 2.1 \pm 1.3$, $n=10$; and $3.27 \pm 2.4, n=22$, respectively).
Additional confirmation of protection against general cartilage destruction was obtained by measuring serum COMP levels. COMP has been validated as a marker of cartilage turnover during experimental arthritis, based on a strong correlation between visual arthritis scores and serum COMP levels (28-30). Significant reduction of serum COMP levels was observed in mice treated either with anti-IL-18 IgG or with 3 $\mathrm{mg} / \mathrm{kg}$ rhIL-18BP, compared with CIA control mice $(P=0.002$ and $P=0.02$, respectively), whereas serum COMP levels in mice treated with $1 \mathrm{mg} / \mathrm{kg}$ rhIL-18BP were not reduced significantly (Figure $3, \mathrm{~b}$ and c).

Effect of treatment on paw swelling and inflammatory synovitis. Anti-IL-18 IgG treatment significantly reduced the inflammatory process as determined by semiquantitative scoring of synovial inflammation $(P<0.001$; Table 1) and the development of paw swelling (Figure 4; $P<0.0001)$. In contrast, rhIL-18BP treatment did not significantly decrease the synovial inflammation score of the first arthritic paw at any of the tested doses (Table 1). Interestingly, when the other paws (first arthritic paw excluded) were analyzed, treatment with $1 \mathrm{mg} / \mathrm{kg}$ and $3 \mathrm{mg} / \mathrm{kg}$ rhIL-18BP significantly reduced the synovial inflammation score $(P<0.05)$. Macroscopic inflammation, measured by the progression of paw swelling, was reduced significantly by the higher doses of rhIL-18BP $(1 \mathrm{mg} / \mathrm{kg}$ and $3 \mathrm{mg} / \mathrm{kg} ; P=0.04)$. However, the treatments with the lower doses of 0.25 $\mathrm{mg} / \mathrm{kg}$ and $0.5 \mathrm{mg} / \mathrm{kg}$ rhIL-18BP had no significant effect on this parameter.

Reduction of serum IL-6 levels after IL-18 neutralization in vivo. To gain some insight into the mechanism of action during IL-18 neutralization, serum levels of IL-6, TNF- $\alpha$, IL- $1 \beta$, and IFN- $\gamma$ were measured in the treated animals at the time of sacrifice. Levels of IL- 6 in the sera of the animals treated with 1 and $3 \mathrm{mg} / \mathrm{kg}$ rhIL-18BP were significantly reduced $(P=0.026$ and $P=0.029$, respectively) compared with saline-treated CIA mice (Figure 5b). Similarly, the levels of bioactive mIL- 6 were also significantly reduced after anti-IL-18 IgG treatment $(P<0.01)$, as shown in Figure 5a. Circulating levels of the other cytokines tested were below the limit of detection. rhIL-18BP decreases IL-18-induced TNF- $\alpha, I L-6$, and IFN- $\gamma$ secretion by peritoneal macrophages in vitro. The contribution of macrophage-derived proinflammatory cytokines in CIA is well established $(23,28)$. Therefore, to investigate a potential mode of action of rhIL-18BP, the ability of rhIL-18BP to control the production of proinflammatory cytokines such as TNF- $\alpha$, IL- 6 , and IFN- $\gamma$ specifically by macrophages was investigated. IL-18 directly promoted TNF- $\alpha$ and IL- 6 secretion by peritoneal macrophages; in contrast, secretion of IFN- $\gamma$ was induced only by the combination of IL-18 and IL-12. As hypothesized, TNF- $\alpha$ and IL-6 levels were reduced to basal values in the presence of rhIL-18BP (Figure 6, a and b; $P=0.001$ and $P=0.0007$, respectively). Interestingly, the inhibitory effect of rhIL-18BP was also observed when these cytokines were induced by the combination of IL-18 

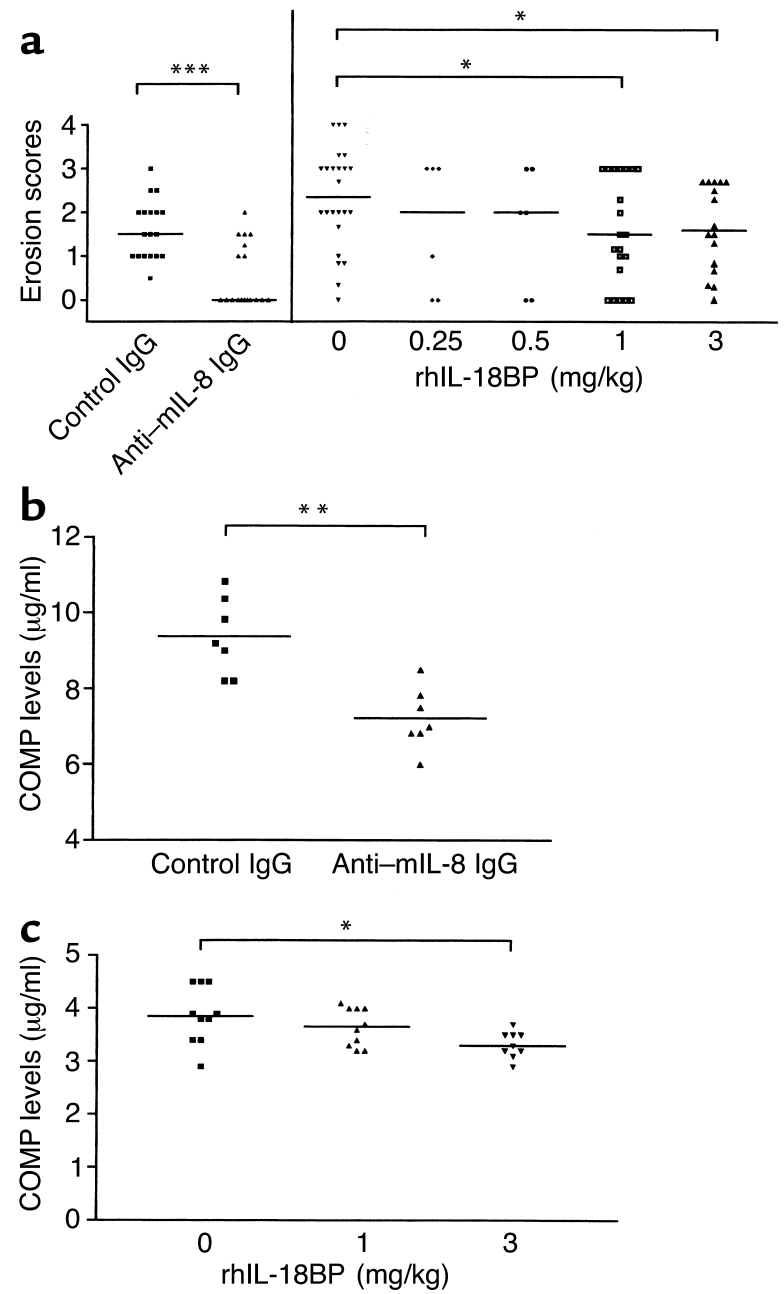

and IL-12 (Figure 6, a and b; $P=0.0009$ and $P=0.0004$, respectively). IFN- $\gamma$ levels were also significantly decreased in the presence of rhIL-18BP (Figure $6 c ; P=0.0001)$. These data demonstrate that neutralization of IL-18 activity results in decreased production of TNF- $\alpha$, IL- 6 , and IFN- $\gamma$ by macrophages, providing a potential explanation for the protective effect observed in vivo.

\section{Discussion}

The present study was conducted to assess the anti-rheumatic therapeutic potential of IL-18 neutralization, by investigating the effect of blocking endogenous IL18 in an experimental model of rheumatoid arthritis. Two distinct IL-18 neutralizing reagents were administered therapeutically to mice with CIA. Our results clearly demonstrate that blocking endogenous IL-18 after disease onset significantly decreases the clinical symptoms of arthritis, and, more importantly, that this

\section{Figure 3}

Neutralization of endogenous IL-18 decreases cartilage destruction in CIA mice. (a) Erosion scores of arthritic joints after treatment with $2 \mathrm{mg} /$ mouse of control IgG (squares), anti-IL-18 IgG (triangles), and $0 \mathrm{mg} / \mathrm{kg}$ (inverted triangles), $0.25 \mathrm{mg} / \mathrm{kg}$ (diamonds), $0.5 \mathrm{mg} / \mathrm{kg}$ (circles), $1 \mathrm{mg} / \mathrm{kg}$ (open squares), and $3 \mathrm{mg} / \mathrm{kg}$ (triangles) of rhlL-18BP, as indicated. ( $b$ and $\mathbf{c}$ ) Quantification of serum levels of COMP, a marker of cartilage turnover, after treatment with $2 \mathrm{mg}$ of normal rabbit IgG (squares) or anti-mIL-18 IgG (triangles) (b), and with saline (0 rhIL-18BP) (squares) or with $1 \mathrm{mg} / \mathrm{kg}$ (triangles) and 3 $\mathrm{mg} / \mathrm{kg}$ (inverted triangles) rhIL-18BP $(\mathbf{c}) .{ }^{*} P<0.05,{ }^{*} P=0.0023$, ${ }^{*} * P=0.0006$, treated versus control groups.

therapeutic approach protects joints from further destruction. The disease-modifying property of the treatment was demonstrated by a significant decrease in cartilage erosion scores and reduction of the levels of COMP in the serum. Neutralization of IL-18 with the antibody, at the single concentration investigated, consistently and significantly reduced all parameters studied, i.e., visual clinical scores, paw swelling, cartilage degradation, levels of serum COMP, and IL-6.

A dose-finding study using rhIL-18BP revealed more complex pharmacodynamics. The effect of this naturally occurring binding molecule appeared to be dependent on a threshold concentration. Cartilage erosions were decreased by the higher doses of 1 and 3 $\mathrm{mg} / \mathrm{kg}$, while the lower doses of 0.25 and $0.5 \mathrm{mg} / \mathrm{kg}$ were insufficient to affect this parameter. Similarly, inflammation, monitored by the progression of paw swelling during the 7-day treatment, was decreased only by the two higher doses. The dose effect on the clinical evolution of disease, monitored by clinical scores, was somewhat different. The clinical scores represent the sum of the scores of all four individual paws, whether diseased or not at initiation of treatment. As the disease develops, randomly and at different times in each paw, this parameter reflects not only the evolution of disease in the affected paw but also the effect of the treatment on further spreading of disease to joints that were healthy at the initiation of the treatment. In this parameter (clinical score), the most
Table 1

Effect of IL-18 neutralization on synovial inflammation

\begin{tabular}{lccccc}
\hline \multicolumn{1}{c}{ Treatment } & \multicolumn{2}{c}{$\begin{array}{c}\text { Synovial inflammation } \\
\text { scores in the first } \\
\text { arthritic paw } \\
\text { (mean } \pm \text { SEM) }\end{array}$} & $\begin{array}{c}\text { Synovial inflammation } \\
\text { scores in the other } \\
\text { three paws } \\
\text { (mean } \pm \text { SEM) }\end{array}$ \\
Control IgG & $2 \mathrm{mg} /$ mouse & $1.85 \pm 0.72$ & $n=18$ & NSc & \\
Anti-IL-18 IgG & $2 \mathrm{mg} /$ mouse & $0.80 \pm 0.60^{* *}$ & $n=18$ & $\mathrm{NSc}$ & \\
rhIL-18BP & $0 \mathrm{mg} / \mathrm{kg}$ & $3.12 \pm 0.20$ & $n=24$ & $5.36 \pm 0.62$ & $n=22$ \\
& $1 \mathrm{mg} / \mathrm{kg}$ & $2.98 \pm 0.40$ & $n=22$ & $3.61 \pm 0.45^{*}$ & $n=30$ \\
& $3 \mathrm{mg} / \mathrm{kg}$ & $3.04 \pm 0.30$ & $n=16$ & $3.43 \pm 0.40^{*}$ & $n=16$
\end{tabular}

Synovial inflammation was scored at the end of the experiments by two independent investigators looking at coded slides. The first clinically affected joint was examined after intraperitoneal treatments with anti-IL-18 IgG and rhIL-18BP, and scored (maximum =4). Scoring of the other three paws in the groups of animals treated with saline, $1 \mathrm{mg} / \mathrm{kg}$ rhIL-18BP, and $3 \mathrm{mg} / \mathrm{kg}$ rhIL-18BP was also performed (maximum $=12$ ). Results obtained for each treated group were compared with its control group. ${ }^{*} P<0.05$, ${ }^{*} P<0.01$. NSc, not scored. 


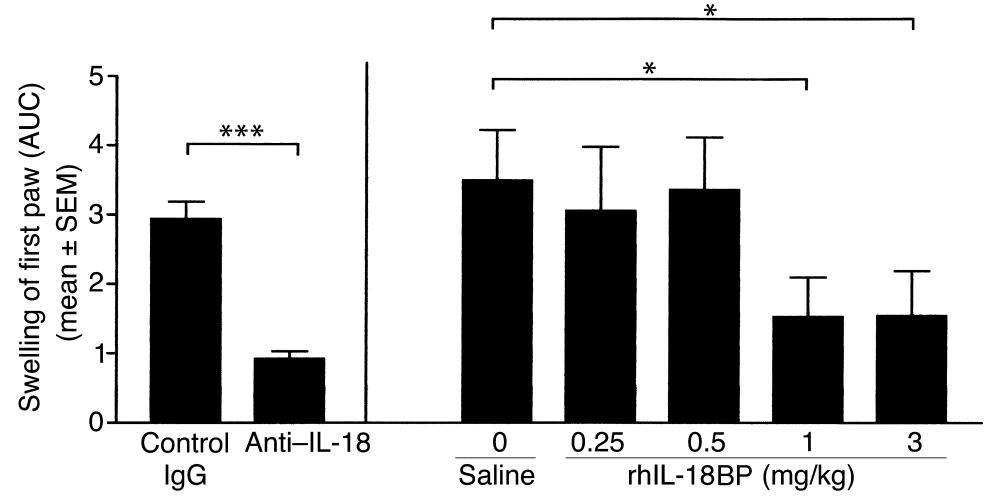

Figure 4

Neutralization of IL-18 decreases paw swelling. Progression of swelling was followed on the first paw that showed clinical signs of disease by measuring paw swelling using precision calipers. Results are expressed as AUC \pm SEM, after treatment with control IgG $(n=9)$ or anti-IL-18 $\operatorname{lgG}(n=9)$ and saline $(n=11)$, or rhIL-18BP at 0.25 $\mathrm{mg} / \mathrm{kg}(n=7), 0.5 \mathrm{mg} / \mathrm{kg}(n=7), 1 \mathrm{mg} / \mathrm{kg}(n=12)$, and $3 \mathrm{mg} / \mathrm{kg}(n=12) .{ }^{*} P \leq 0.05$, ***P<0.0001, treated versus control groups.

efficient doses were 0.5 and $1 \mathrm{mg} / \mathrm{kg}$, whereas 0.25 $\mathrm{mg} / \mathrm{kg}$ was insufficient and $3 \mathrm{mg} / \mathrm{kg}$ was less efficient. The smaller effect on the clinical score with the dose of $3 \mathrm{mg} / \mathrm{kg}$ was unexpected.

Several hypotheses can be put forward to explain these results. One possible explanation is the induction of a neutralizing antibody response to the binding protein in the animals receiving the higher concentrations of rhIL-18BP. We know that such a neutralizing polyclonal antiserum can be obtained. Unfortunately, the high levels of residual rhIL-18BP present in our treated CIA mice precluded the formal testing of this hypothesis. Another possibility is that at this high concentration, rhIL-18BP acts as a depot for IL-18, preventing clearance, or that it binds to another related molecule. Unlike soluble cytokine receptors, IL-18BP is not related to the ligand-binding chain of the IL-18R. However, it is clear that the cytokine IL-18 binds to both the soluble IL-18BP and the cell-bound IL-18R. A recently reported molecule, IL-1H4 (a human IL-1 homologue) has been shown to bind to IL-18R $(31,32)$. IL-1H4 has a high degree of homology to IL-18. It is therefore possible that IL-18BP binds IL-1H4. Because IL-1H4 binds to IL-18R, the possibility exists that it would antagonize IL-18. A similar example has been reported with IL-1 homologues that have high homology to IL-1Ra and have been shown to be antagonists (33) and to block IL-1 (weakly). If IL-18BP binds IL-1H4 at high concentrations, this may explain the results observed with the different doses of rhIL-18BP.

\section{Figure 5}

Neutralization of endogenous IL-18 decreases circulating levels of IL-6. (a) IL-6 bioactivity present in serum of arthritic mice treated with either control IgG or anti-IL-18 IgG $(n=9)$. (b) IL-6 levels measured by ELISA in the serum of arthritic mice treated with either saline or rhIL-18BP $(n=10) .{ }^{*} P<0.05,{ }^{*} P<0.01$, treated versus control groups.
Anti-IL-18 IgG and rhIL-18BP treatments had different effects on the synovial inflammation that was assessed by scoring cellular infiltration and synovial hyperplasia. Whereas the antibody treatment decreased synovial inflammation in the first arthritic paw, treatment with rhIL-18BP had no effect at any of the doses tested, although at the higher doses the treatment was active in reducing cartilage degradation. This suggests that antibody therapy is effective in decreasing cellular infiltration to joints, synovial hyperplasia, and release of destructive enzymes, whereas the binding protein, at the concentrations tested, is efficient at decreasing the release of destructive enzymes but has no effect on cellular infiltration and synovial hyperplasia. However, our data showing decreased synovial inflammation in paws other than the first arthritic paw suggest that neutralization of IL-18 activity acts preventatively to protect from de novo synovitis during the course of the disease.

Induction of CIA in DBA/1 mice lacking IL-18 showed reduced incidence and severity of disease, with a significant decrease in articular destruction of the first arthritic paw compared with that of the wild-type control mice (34). Interestingly, synovial hyperplasia and cellular infiltration were not significantly reduced in the absence of IL-18; this is similar to what we observed after rhIL-18BP treatment of wild-type DBA/1 CIA mice.

IL-18 has been reported to act directly on synovial macrophages and articular chondrocytes. In vitro experiments have demonstrated that IL-18 induces

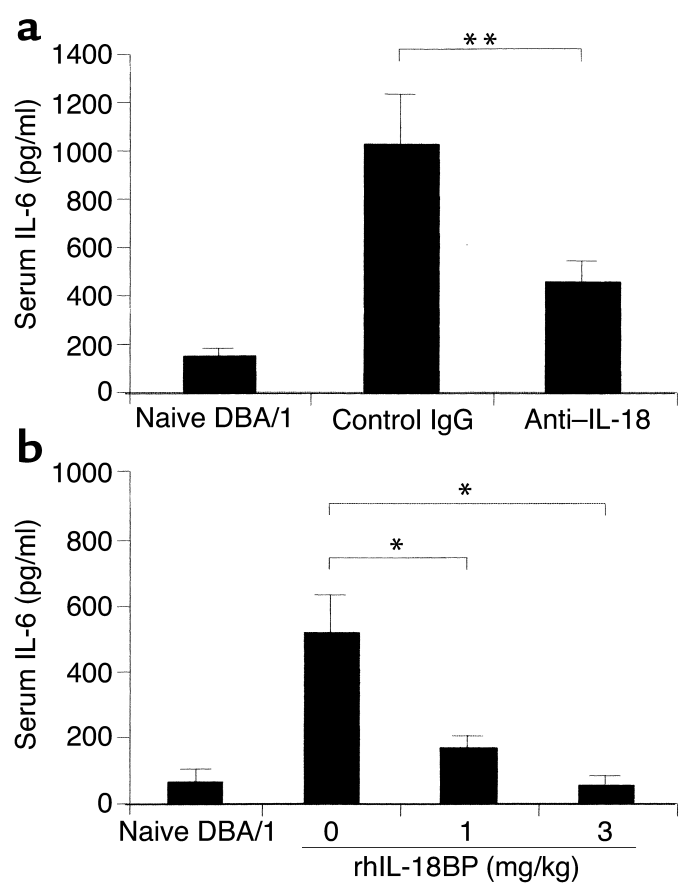


the release of proinflammatory cytokines by macrophages, including TNF- $\alpha$, as well as release of matrix metalloproteinases and glycosaminoglycan by articular cartilage, supporting a possible direct contribution of IL-18 in joint destruction (12).

Recently, IL-18 was reported to enhance CIA in $\mathrm{DBA} / 1$ mice injected with CII in incomplete FA (35). Coadministration of IL-18 changed the low-grade arthritis seen in DBA/1 mice treated with CII in incomplete FA to arthritis that was indistinguishable from that in mice treated with CII in CFA. Treatment with IL-12 alone or with IL-18 alone promotes CIA, which is enhanced further by treatment with combined IL-12 and IL-18. IL-18-treated mice produce more TNF- $\alpha$ and IL-6, through direct effects on macrophages, but less IFN- $\gamma$, than do mice treated with IL-12. The role of IL-18 together with IL-12 in the synovium of rheumatoid arthritis may be that of a potent inducer of TNF- $\alpha$, IL- 6 , and IFN- $\gamma$ production by locally accumulated macrophages and $\mathrm{T}$ cells that sustain the inflammatory response in the joints. Indeed, our in vitro experiments demonstrate that IL-18 can directly stimulate macrophages to secrete TNF- $\alpha$, IL- 6 , and IFN- $\gamma$ when IL-18 is combined with IL-12, and that the induction of these proinflammatory cytokines is inhibited in the presence of rhIL-18BP. In vivo treatment with 1 and $3 \mathrm{mg} / \mathrm{kg}$ rhIL-18BP resulted in high levels of circulating rhIL-18BP ( $23.1 \pm 4$ and $74.2 \pm 6.3 \mathrm{ng} / \mathrm{ml}$, respectively, $n=5$ in each group) measured on the day of sacrifice. These levels of rhIL-18BP have the potential to completely neutralize endogenous IL-18 activity, and therefore account for the protective effect observed.

We observed increased levels of IL-18 and IL- 6 during the development of CIA, and the levels of IL-6 were significantly reduced by treatment with IL-18 neutralizing agents. Unfortunately, the effect of the treatment on TNF- $\alpha$ and IFN- $\gamma$ could not be studied, because circulating levels of these cytokines were below the detection limits of the assays, even in the untreated arthritic animals.

Anti-IL-18 IgG and rhIL-18BP may have distinct mechanisms of action. IL-18BP bioactivity is not fully understood; also, anti-IL-18 IgG may have activities in addition to the neutralization of IL-18, such as modulation of the $\mathrm{B}$ cell response that is also known to be involved in the development of CIA. Collagen-specific IgG2a antibodies, which are typically produced during a Th1 response, were unaffected by the rhIL-18BP treatment; in contrast, their titers were significantly decreased in anti-IL-18 IgG treated mice compared with mice treated with control IgG (data not shown). This inhibition of the collagen-specific $\mathrm{B}$ cell response, observed only after anti-IL-18 treatment, may involve crosslinking of antigen receptors with Fc receptors, and highlights potential immunomodulation that is specific to antibody treatment.

Other functions of IL-18 may also be deleterious in rheumatoid arthritis, further supporting the thera- peutic strategy of neutralizing this cytokine in this disease. A recent communication has reported evidence for IL-18 promoting synovial inflammation through activation and recruitment of polymorphonuclear neutrophils in the synovial compartment (36). Large numbers of these cells are present in synovial fluid and at the cartilage-pannus junction of the synovium, which is the site of ongoing destruction. Activated neutrophils can release proinflammatory cytokines, including TNF- $\alpha$ and IL- $1 \beta$, and destructive proteins such as matrix metalloproteinases.
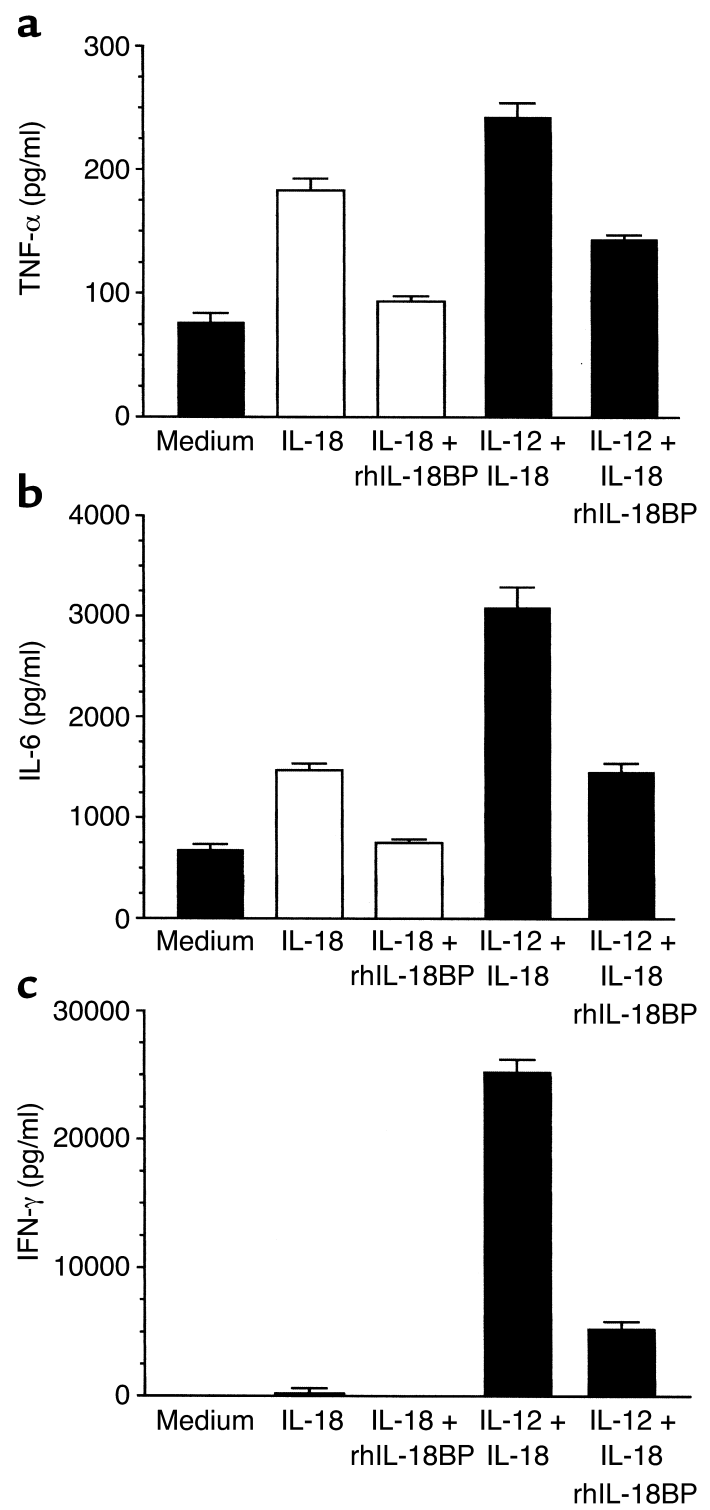

Figure 6

rhIL-18BP regulates IL-18-induced TNF- $\alpha$, IL- 6 , and IFN- $\gamma$ production by peritoneal macrophages. Macrophages from DBA/ 1 mice were enriched by plastic adherence and stimulated with $200 \mathrm{ng} / \mathrm{ml}$ IL-18 (open bars), a combination of IL-12 (100 ng/ml) and IL-18 (200 $\mathrm{ng} / \mathrm{ml})$, or cultured with medium alone (black bars), in the absence or presence of rhlL-18BP $(1 \mu \mathrm{g} / \mathrm{ml})$. Cytokine levels in 24hour culture supernatants were measured by ELISA. Data are expressed as mean \pm SEM of triplicate cultures. 
Although the precise mechanisms of action of this therapeutic approach are not fully understood, the disease-modifying activity of IL-18 neutralization in an experimental model of rheumatoid arthritis provides a rationale to test such a strategy in the clinic.

\section{Acknowledgments}

We are grateful to Dick Heinegård and Tore Saxne from the Department of Cell and Molecular Biology, Lund University, Lund, Sweden, for serum COMP determination, and John Challier of Serono Pharmaceutical Research Institute (SPRI) for excellent technical support. We are most grateful to Marie Kosco-Vilbois of SPRI for many supportive discussions and active help with the preparation of this manuscript. Chris Hebert from SPRI is thanked for his help with the illustrations.

1. Nakamura, K., Okamura, H., Wada, M., Nagata, K., and Tamura, T. 1989. Endotoxin-induced serum factor that stimulates gamma interferon production. Infect. Immun. 57:590-595.

2. Ushio, S., et al. 1996. Cloning of the cDNA for human IFN-gammainducing factor, expression in Escherichia coli, and studies on the biologic activities of the protein. J. Immunol. 156:4274-4279.

3. Kohno, K., et al. 1997. IFN-gamma-inducing factor (IGIF) is a costimulatory factor on the activation of Th1 but not Th2 cells and exerts its effect independently of IL-12. J. Immunol. 158:1541-1550.

4. Okamura, H., Tsutsui, H., Kashiwamura, S., Yoshimoto, T., and Nakanishi, K. 1998. Interleukin-18: a novel cytokine that augments both innate and acquired immunity. Adv. Immunol. 70:281-312.

5. Puren, A.J., Fantuzzi, G., Gu, Y., Su, M.S., and Dinarello, C.A. 1998. Interleukin-18 (IFN- $\gamma$-inducing factor) induces IL- 8 and IL- $1 \beta$ via TNF- $\alpha$ production from non-CD14+ human blood mononuclear cells. J. Clin. Invest. 101:711-721.

6. Kohno, K., and Kurimoto, M. 1998. Interleukin 18, a cytokine which resembles IL-1 structurally and IL-12 functionally but exerts its effect independently of both. Clin. Immunol. Immunopathol. 86:11-15.

7. Okamura, H., et al. 1995. Cloning of a new cytokine that induces IFNgamma production by T cells. Nature. 378:88-91.

8. Takeda, K., et al. 1998. Defective NK cell activity and Th1 response in IL18-deficient mice. Immunity. 8:383-390.

9. Gu, Y., et al. 1997. Activation of interferon-gamma inducing factor mediated by interleukin-1beta converting enzyme. Science. 275:206-209.

10. Stoll, S., et al. 1998. Production of functional IL-18 by different subtypes of murine and human dendritic cells (DC): DC-derived IL-18 enhances IL-12-dependent Th1 development. Eur. J. Immunol. 28:3231-3239.

11. Brossart, P., et al. 1998. Generation of functional human dendritic cells from adherent peripheral blood monocytes by CD40 ligation in the absence of granulocyte-macrophage colony-stimulating factor. Blood. 92:4238-4247.

12. Olee, T., Hashimoto, S., Quach, J., and Lotz, M. 1999. IL-18 is produced by articular chondrocytes and induces proinflammatory and catabolic responses. J. Immunol. 162:1096-1100.

13. Udagawa, N., et al. 1997. Interleukin-18 (interferon-gamma-inducing factor) is produced by osteoblasts and acts via granulocyte/macrophage colony-stimulating factor and not via interferon-gamma to inhibit osteoclast formation. J. Exp. Med. 185:1005-1012.
14. Akira, S. 2000. The role of IL-18 in innate immunity. Curr. Opin. Immunol. 12:59-63.

15. Dinarello, C.A. 2000. Interleukin-18, a proinflammatory cytokine. Eur. Cytokine Netw. 11:483-486.

16. Gracie, J.A., et al. 1999. A proinflammatory role for IL-18 in rheumatoid arthritis. J. Clin. Invest. 104:1393-1401.

17. Saha, N., et al. 1999. Interleukin-1beta-converting enzyme/caspase-1 in human osteoarthritic tissues: localization and role in the maturation of interleukin-1 beta and interleukin 18. Arthritis Rheum. 42:1577-1587.

18. Joosten, L.A., et al. 2000. An IFN-gamma-independent proinflammatory role of IL-18 in murine streptococcal cell wall arthritis. J. Immunol. 165:6553-6558.

19. Novick, D., et al. 1999. Interleukin-18 binding protein: a novel modulator of the Th1 cytokine response. Immunity. 10:127-136.

20. Aizawa, Y., et al. 1999. Cloning and expression of interleukin-18 binding protein. FEBS Lett. 445:338-342.

21. Kim, S.H., et al. 2000. Structural requirements of six naturally occurring isoforms of the IL-18 binding protein to inhibit IL-18. Proc. Natl. Acad. Sci. USA. 97:1190-1195.

22. Durie, F.H., et al. 1993. Prevention of collagen-induced arthritis with an antibody to gp39, the ligand for CD40. Science. 261:1328-1330.

23. Williams, R.O., Feldmann, M., and Maini, R.N. 1992. Anti-tumor necrosis factor ameliorates joint disease in murine collagen-induced arthritis. Proc. Natl. Acad. Sci. USA. 89:9784-9788.

24. Plater-Zyberk, C., and Bonnefoy, J.Y. 1995. Marked amelioration of established collagen-induced arthritis by treatment with antibodies to CD23 in vivo. Nat. Med. 1:781-785.

25. Plater-Zyberk, C., Taylor, P.C., Blaylock, M.G., and Maini, R.N. 1994. Anti-CD5 therapy decreases severity of established disease in collagen type II-induced arthritis in DBA/1 mice. Clin. Exp. Immunol. 98:442-447.

26. Joosten, L.A., et al. 1997. Role of interleukin-4 and interleukin-10 in murine collagen-induced arthritis. Protective effect of interleukin- 4 and interleukin-10 treatment on cartilage destruction. Arthritis Rheum. 40:249-260.

27. Fantuzzi, G., Puren, A.J., Harding, M.W., Livingston, D.J., and Dinarello, C.A. 1998. Interleukin-18 regulation of interferon gamma production and cell proliferation as shown in interleukin-1beta-converting enzyme (caspase-1)-deficient mice. Blood. 91:2118-2125.

28. Joosten, L.A., et al. 1999. IL-1 alpha beta blockade prevents cartilage and bone destruction in murine type II collagen-induced arthritis, whereas TNF-alpha blockade only ameliorates joint inflammation. J. Immunol. 163:5049-5055.

29. Carlsen, S., Hansson, A.S., Olsson, H., Heinegard, D., and Holmdahl, R. 1998. Cartilage oligomeric matrix protein (COMP)-induced arthritis in rats. Clin. Exp. Immunol. 114:477-484.

30. Joosten, L.A., et al. 1999. Protection against cartilage and bone destruction by systemic interleukin- 4 treatment in established murine type II collagen-induced arthritis. Artbritis Res. 1:81-91.

31. Pan, G., et al. 2001. IL-1H, an interleukin 1-related protein that binds IL18 receptor/IL-1Rrp. Cytokine. 13:1-7.

32. Kumar, S., et al. 2000. Identification and initial characterization of four novel members of the interleukin-1 family. J. Biol. Chem. 275:10308-10314.

33. Campbell, I.K., Gerondakis, S., O'Donnell, K., and Wicks, I.P. 2000. Distinct roles for the NF- $\mathrm{KB} 1$ ( $\mathrm{p} 50)$ and c-Rel transcription factors in inflammatory arthritis. J. Clin. Invest. 105:1799-1806.

34. Wei, X.Q., Leung, B.P., Arthur, H.M., McInnes, I.B., and Liew, F. Y. 2001. Reduced incidence and severity of collagen-induced arthritis in mice lacking IL-18. J. Immunol. 166:517-521.

35. Leung, B.P., McInnes, I.B., Esfandiari, E., Wei, X.Q., and Liew, F. Y. 2000. Combined effects of IL-12 and IL-18 on the induction of collageninduced arthritis. J. Immunol. 164:6495-6502.

36. Leung, B.P., et al. 2000. Interleukin-18 can promote synovial inflammation through activation of peripheral blood and synovial neutrophils. Arthritis Rheum. 43:1253. 